\title{
Focused Versus Conventional Radiotherapy in Spinal Oncology: Is There any Difference in Fusion Rates and Pseudoarthrosis?
}

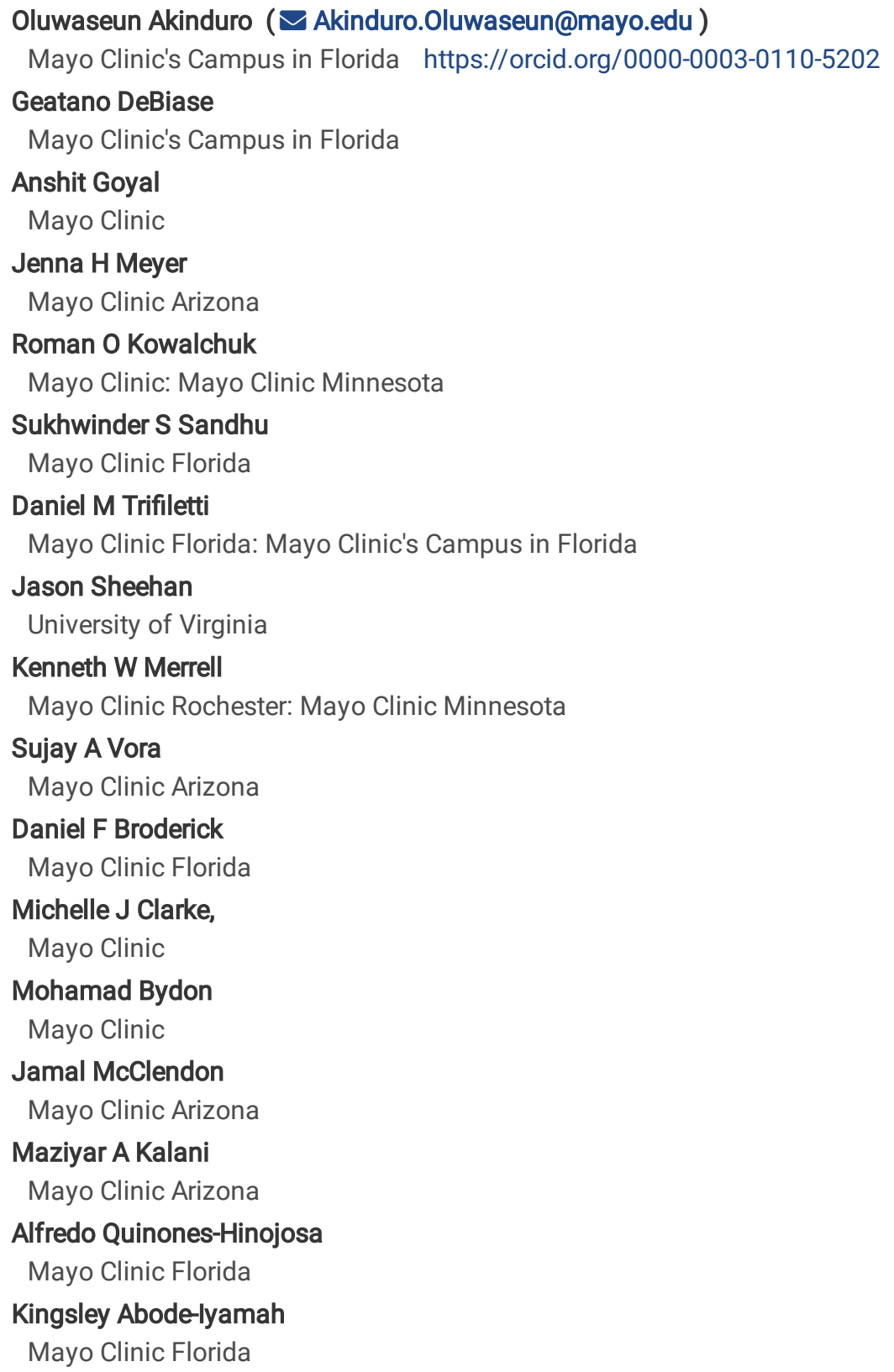

\section{Research Article}

Keywords: Focused radiotherapy, conventional radiotherapy, external beam radiation, stereotactic body radiotherapy, pseudoarthrosis, nonunion

Posted Date: October 29th, 2021

DOI: https://doi.org/10.21203/rs.3.rs-973693/v1

License: (c) (i) This work is licensed under a Creative Commons Attribution 4.0 International License. Read Full License 
Version of Record: A version of this preprint was published at Journal of Neuro-Oncology on January 7th, 2022. See the published version at https://doi.org/10.1007/s11060-021-03915-3. 


\section{Abstract}

Introduction

Radiotherapy is considered standard of care for adjuvant peri-operative treatment of many spinal tumors, including those with instrumented fusion. Unfortunately, radiation treatment has been linked to increased risk of pseudoarthrosis. Newerfocused radiotherapy strategies with enhanced conformalitycould offer improved fusion rates for these patients, but this has not been confirmed.

Methods

We performed a retrospective analysis of patients at three tertiary care academic institutions withprimary and secondary spinal malignancies that underwent resection, instrumented fusion, and peri-operative radiotherapy. Two board certified neuro-radiologists used theLenke fusion score to grade fusion status at 6 and 12-months after surgery. Secondary outcomes includedclinical pseudoarthrosis, wound complications, and the effect of radiation timing, radiobiological dose delivered, the use of photons versus protons, tumor type, tumor location, and use of autograft on fusion outcomes.

Results

After reviewof 1252 spinal tumor patients, there were 60 patients with at least 6 months follow-up that were included in our analyses. Twenty-five of these patients received focused radiotherapy,20 patients received conventional radiotherapy, and 15 patients were treated with protons. There was no significant difference between the groups for covariates such assmoking status,obesity, diabetes, intraoperative use of autograft, and use of peri-operative chemotherapy. There was a significantly higher rate of fusion for patients treated with focused radiotherapy compared to those treated with conventional radiotherapy at 6 -months $(64.0 \%$ versus $30.0 \%$, Odds ratio: $4.15, \mathrm{p}=0.036)$ and 12 months $(80.0 \%$ versus $42.1 \%$, OR: $5.50, p=0.022)$. There was a significantly higher rate of clinical pseudoarthrosis in the conventional radiotherapy cohortcompared to patients in the focused radiotherapy cohort $(19.1 \%$ versus $0 \%, p=0.037)$. There was no difference in fusion outcomes for any of the secondary outcomes except for use of autograft. The use ofintra-operative autograft was associated with an improved fusion at 12 -months $(66.7 \%$ versus $37.5 \%$, OR: $3.33, \mathrm{p}=0.043)$.

Conclusion

Focused radiotherapy may be associated withan improved rate of fusion and clinical pseudoarthrosis when compared to conventional radiation delivery strategiesin patients with spinal tumors. Use of autograft at the time of surgery may be associated with improved 12month fusion rates.Further large-scale prospective and randomized controlled studies are needed to better stratify the effects of radiation delivery modality in these patients.

\section{Introduction}

Radiotherapy is an integral component of conventional treatment strategies for primary and secondary tumors of the spinal cord and column. The past decade has seen a significant advancement in the available technologies for delivery of radiation. [1][2, 3] This includes stereotactic body radiotherapy (SBRT) and proton-based radiation, which have both seen a surge in applications for various spinal pathologies. [4][5][6] Despite the necessity of radiation therapy in combination with surgery for adjuvant treatment of many spine tumors, radiation inhibits bone formation and therefore leads to increased risk of instrumentation failure and non-union. [7] Preclinical studies have shown that ionizing radiation induced double stranded DNA breaks have a direct effect on bone forming osteoblasts. [8] Interestingly, low dose radiation promotes osteogenesis, but high dose radiation, as is required for tumor control, inhibits bone growth. [8][9] lonizing radiation enacts its effects on bone growth through various mechanisms, including cell cycle arrest, inhibiting collagen formation, regulation of vascular endothelial growth factor, and inhibition of osteoblast proliferation. [8][9][10, 11]

There is a paucity of literature describing the fusion outcomes for patients with spinal tumors, as most of these patients have metastatic disease and historically succumbed to their primary disease prior to the time that their fusion should be solid. [12] Due to tremendous advancements in targeted therapies and surgical strategies, patients live longer with their cancers, increasing the importance of preserving of quality of life in these patients after their surgery. [13][14] Non-union can lead to debilitating pain, need for further surgery, and decreased quality of life for patients following instrumentation. The rates of pseudoarthrosis range from 5-35\% following spinal instrumentation, with these rates being higher for those requiring radiation, so any efforts to enhance the likelihood of fusion for these patients will be of great benefit to them. [15][16][17]

The primary aim of this study is to assess the 6 and 12-month fusion rates in patients who underwent surgical resection with instrumentation for their spinal tumors and received radiotherapy with either conventional or focused delivery strategies. Secondary aims

Page $3 / 13$ 
were to assess the impact of radiation timing, number of fractions, dose, use of photons or protons, and use of autograft on fusion rates. We hypothesize that fusion rates will be improved in those patients treated with focused radiation delivery strategies.

\section{Methods}

\section{Patient Population}

The authors performed a retrospective analysis of patients at each of the three sites of our tertiary care academic institution from January 2013 to October 2020. This study was approved by the institutional IRB committee (IRB\# 18-003951). The inclusion criteria were as follows: 1) adult patients with resection of a primary or secondary tumor of the spinal cord or column, 2) patients with instrumented fusion using rods and screws after their surgical resection, and 3) patients who received radiation treatment either before or after their surgical procedure. The exclusion criteria were as follows: 1) patients with less than 6-months of radiographic and clinical follow-up, 2) patients who received instrumentation using carbon-based hardware, 3) patients who received cement augmentation with their instrumentation. The purpose of this manuscript was not to assess the efficacy of newer instrumentation techniques such as fenestrated polymethylmethacrylate (PMMA)augmented pedicle screw fixation, or carbon-based hardware, therefore we excluded these patients, as they would likely confound the results. We collected patient-specific variables such as age, sex, pathology diagnosis, smoking status at the time of surgery, post-operative wound issues, BMI, and diabetic status.

\section{Radiation Treatment}

We collected variables related to the radiotherapy including delivery modality, number of fractions, timing of radiation, and radiation dosage. Radiation modalities were grouped to consider the conformality of the radiotherapy as a potential predictor of the rate of fusion. "Focused radiation" was defined as those treatment plans that received greater than 5Gy per fraction using technology to maximize the conformality with steep dose gradients. This included intensity-modulated radiation therapy (IMRT) and stereotactic body radiation therapy (SBRT) plans (Figure 1). $[18,19]$ Conventional radiation was defined as 3-dimensional external beam radiotherapy treatment plans (less than 5Gy per fraction, including plans with $8 \mathrm{~Gy}$ in 1 fraction), which did not use IMRT. [20] Proton-based radiation was considered in a separate group, due to inherent differences in treatment planning and underlying radiobiology. [21] We assessed the radiobiological effect by calculating the biologically effective dose (BED) for each patient and then compared patients above and below the median BED.

\section{Outcomes}

The primary outcome was fusion status as determined by two board-certified neuro-radiologists using X-ray and CT images. Each radiologist was blinded to the radiation status of the cohort, and they assessed each patient separately and discussed the discrepancies. The Lenke fusion scale was used to assess fusion at 6 and 12-months after placement of instrumentation. [22] The neuro-radiologists each assessed the fusion across the posterior elements on imaging since not every patient will have an interbody graft. Patients were classified in binary groups as fused with Lenke grade A or B, or non-fused with a Lenke grade of C or D (Figure 2). Secondary outcomes included the rate of clinically significant pseudoarthrosis, defined as those patients with radiographic evidence of pseudoarthrosis, who demonstrated new onset of pain and/or weakness which was attributed to their non-union. We compared data regarding post-operative wound complications for the groups. We analyzed the effect radiation timing (pre-versus post-operative \& within 1-month of surgery versus $>1$-month from surgery), dose (above versus below median BED), photons versus protons, primary versus secondary tumors, and use of intra-operative autograft on fusion outcomes.

\section{Statistical Analysis}

Statistical analyses were performed using the Fisher exact test, Student t-test, and Mann-Whitney U test for categorical, parametric continuous, and nonparametric continuous variables, respectively. Odds ratios were calculated based on effect sizes and Baptista-Pike was used to determine exact and mid confidence intervals. Analyses were performed using GraphPad Prism 9.1.0, GraphPad Software, San Diego, California USA.

\section{Results}

\section{Patient demographics}

We reviewed of 1252 patients with spinal tumors treated at our institutions within the time frame, resulting in 60 patients with at least 6months of follow-up (mean follow-up: 33 months; standard deviation: 25.3 months) that were included in our analyses (Figure 3). Thirtyseven (61.6\%) of these patients were male, with a mean age of 63.6 years and a mean follow-up time of 33 months (SD 25.3 months)

Page $4 / 13$ 
(Table 1). Twenty-five of these patients received focused radiotherapy modalities including SBRT ( $\mathrm{n}=17)$ and IMRT ( $\mathrm{n}=8)$. Twenty patients received conventional radiation delivery modalities, and 15 patients received proton-based radiotherapy. The cohorts were well-matched with no significant difference between them for confounders such as smoking status $(p=0.309)$, obesity $(p=0.515)$, diabetes $(p=0.365)$, tumor type ( $p=>0.999)$, intraoperative use of autograft ( $p=>0.999)$, and use of peri-operative chemotherapy drugs such as nivolumab, ipilimumab, imatinib, cisplatin, and paclitaxel $(p=>0.999)$. There were also similar numbers of levels fused with an average of 5.2 levels per patient in the focused radiotherapy 5.5 levels per patients in the conventional radiotherapy group $(p=0.602)$. There was a trend towards a higher incidence of local recurrence in the conventional radiotherapy group at the time of fusion assessment ( 8.3 versus $35 \%, p=0.057)$. There were 34 patients with metastatic disease, 15 patients with chordoma, 2 patients with sarcoma, 2 patients with plasmacytoma, 2 patients with lymphoma, 2 patients with spinal cord gliomas, 1 patient with chondrosarcoma, 1 patient with melanocytoma, and 1 patient with atypical meningioma.

\section{Effect of Radiotherapy Delivery Technique}

There was a significantly higher rate of fusion for patients with focused radiotherapy compared to those with conventional radiotherapy at 6-months (64.0\% versus 30.0\%, OR: 4.15, p=0.036) 12-months ( $80.0 \%$ versus $42.1 \%$, OR: 5.50, $\mathbf{p}=0.022)($ Table 2$)$. There was a near significant increase in the incidence of clinically significant pseudoarthrosis in the conventional radiation cohort ( $19.1 \%$ versus $0 \%$, $\mathbf{p}=\mathbf{0 . 0 3 6}$ ), although only one patient required revision surgery for pseudoarthrosis (Table 3 ). There was no significant difference in the incidence of peri-operative wound healing complications between patients treated with focused radiotherapy and those treated with conventional radiotherapy $(16.0 \%$ versus $5.0 \%, p=0.727)$. There were $88 \%$ of patients with $\mathrm{CT}$ scans available for review, with the remaining $12 \%$ of patients being evaluated using $x$-ray imaging.

\begin{tabular}{|c|c|c|c|c|c|c|c|c|c|}
\hline & $\begin{array}{l}\text { Median } \\
\text { Age } \\
\text { (years) }\end{array}$ & M: F & Smoker & Obesity & Diabetes & $\begin{array}{l}\text { Use of } \\
\text { Autograft }\end{array}$ & $\begin{array}{l}\text { Use of } \\
\text { Chemotherapy }\end{array}$ & $\begin{array}{l}\text { Wound } \\
\text { Complications }\end{array}$ & $\begin{array}{l}\text { Clinically } \\
\text { Significant } \\
\text { Pseudoarthrosis }\end{array}$ \\
\hline $\begin{array}{l}\text { All Patients } \\
(n=60)\end{array}$ & 63.6 & $37: 23$ & $\begin{array}{l}6.7 \% \\
(n=4)\end{array}$ & $\begin{array}{l}31.7 \% \\
(n=19)\end{array}$ & $\begin{array}{l}23.3 \% \\
(n=14)\end{array}$ & $\begin{array}{l}46.4 \% \\
(n=26)^{a}\end{array}$ & $26.7 \%(n=16)$ & $15.0 \%,(n=9)$ & $8.3 \%(n=5)$ \\
\hline $\begin{array}{l}\text { Focused } \\
\text { Radiotherapy } \\
(n=25)\end{array}$ & 65.1 & $13: 12$ & $\begin{array}{l}4.0 \% \\
(n=1)\end{array}$ & $\begin{array}{l}24.0 \% \\
(n=6)\end{array}$ & $\begin{array}{l}29.0 \% \\
(n=8)\end{array}$ & $\begin{array}{l}45.8 \% \\
(n=11)^{b}\end{array}$ & $32.0 \%(n=8)$ & $16.0 \%,(n=4)$ & $0.0 \%(n=0)$ \\
\hline $\begin{array}{l}\text { Conventional } \\
\text { Radiotherapy } \\
(n=20)\end{array}$ & 60.6 & $15: 5$ & $\begin{array}{l}15.0 \% \\
(n=3)\end{array}$ & $\begin{array}{l}35.0 \% \\
(n=7)\end{array}$ & $\begin{array}{l}17.2 \% \\
(n=2)\end{array}$ & $\begin{array}{l}41.2 \% \\
(n=7)^{c}\end{array}$ & $24.1 \%(n=7)$ & $5.0 \%(n=1)$ & $15.0 \%(n=3)$ \\
\hline $\begin{array}{l}\text { Proton-based } \\
\text { Radiotherapy } \\
\text { (15) }\end{array}$ & 65.1 & $9: 6$ & $\begin{array}{l}0 \% \\
(n=0)\end{array}$ & $\begin{array}{l}40.0 \% \\
(n=6)\end{array}$ & $\begin{array}{l}26.7 \% \\
(n=4)\end{array}$ & $\begin{array}{l}41.2 \% \\
(n=8)\end{array}$ & $13.3 \%(n=2)$ & $20.0 \%(n=3)$ & $13.3 \%(n=2) *$ \\
\hline \multicolumn{10}{|c|}{ a Data missing for 4 patients, ${ }^{b}$ Data missing for 1 patient, ${ }^{c}$ Data missing for 3 patients } \\
\hline * One patient & quired reo & eration & r pseudos & throsis & & & & & \\
\hline
\end{tabular}




\begin{tabular}{|c|c|c|c|c|c|c|}
\hline & 6-Month Fusion Rate & $\begin{array}{l}\text { Odds } \\
\text { Ratio } \\
\text { (Cl) }\end{array}$ & & 12-Month Fusion Rate & $\begin{array}{l}\text { Odds } \\
\text { Ratio (Cl) }\end{array}$ & \\
\hline \multirow[t]{2}{*}{ Focused Versus Conventional } & \multirow{2}{*}{$\begin{array}{l}\text { Focused: } 64.0 \%, \\
\text { Conventional: } 30.0 \%\end{array}$} & 4.15 & \multirow[t]{2}{*}{$p=0.036$} & \multirow{2}{*}{$\begin{array}{l}\text { Focused: } 80.0 \% \text {, } \\
\text { Conventional: } 42.1 \%\end{array}$} & 5.50 & \multirow[t]{2}{*}{$p=0.022$} \\
\hline & & $\begin{array}{l}(1.10- \\
12.71)\end{array}$ & & & $\begin{array}{l}(1.34 \text { to } \\
18.83)\end{array}$ & \\
\hline \multirow{2}{*}{$\begin{array}{l}\text { Preoperative Radiation Versus } \\
\text { Postoperative Radiation }\end{array}$} & \multirow{2}{*}{$\begin{array}{l}\text { Preoperative: } 42.9 \% \text {, } \\
\text { Postoperative: } 45.7 \%\end{array}$} & 0.89 & \multirow[t]{2}{*}{$p=>0.999$} & \multirow{2}{*}{$\begin{array}{l}\text { Preoperative: } 50.0 \% \text {, } \\
\text { Postoperative: } 57.1 \%\end{array}$} & \multirow{2}{*}{$\begin{array}{l}0.75 \\
(0.20- \\
2.88)\end{array}$} & \multirow[t]{2}{*}{$p=0.734$} \\
\hline & & $\begin{array}{l}(0.25- \\
2.77)\end{array}$ & & & & \\
\hline \multirow[t]{2}{*}{ High Versus Low BED Dosage } & \multirow{2}{*}{$\begin{array}{l}\text { High BED: } 52.2 \% \text {, Low } \\
\text { BED: } 42.1 \%\end{array}$} & 1.44 & \multirow[t]{2}{*}{$p=0.585$} & \multirow{2}{*}{$\begin{array}{l}\text { High BED: } 68.2 \% \text {, Low } \\
\text { BED: } 56.3 \%\end{array}$} & 1.67 & \multirow[t]{2}{*}{$p=0.5105$} \\
\hline & & $\begin{array}{l}(0.49- \\
4.04)\end{array}$ & & & $\begin{array}{l}(0.40- \\
5.72)\end{array}$ & \\
\hline Timing of Radiation & $\begin{array}{l}\text { S } 1 \text { month: } 42.9 \%,>1 \\
\text { month: } 48.4 \%\end{array}$ & $\begin{array}{l}0.80 \\
(0.27- \\
2.46)\end{array}$ & $p=0.781$ & $\begin{array}{l}\text { < } 1 \text { month: } 63.2 \%,>1 \\
\text { month: } 48.3 \%\end{array}$ & $\begin{array}{l}1.84(0.54 \\
-6.03)\end{array}$ & $p=0.382$ \\
\hline Proton Versus Photon & $\begin{array}{l}\text { Protons: } 33.3 \% \text {, Photons: } \\
56.1 \%\end{array}$ & $\begin{array}{l}0.39 \\
(0.12- \\
1.44)\end{array}$ & $p=0.227$ & $\begin{array}{l}\text { Protons: } 35.7 \% \text {, } \\
\text { Photons: } 64.1 \%\end{array}$ & $\begin{array}{l}0.31 \\
(0.09- \\
1.03)\end{array}$ & $p=0.115$ \\
\hline $\begin{array}{l}\text { Primary versus secondary } \\
\text { tumors }\end{array}$ & $\begin{array}{l}\text { Primary: } 40.0 \% \\
\text { Secondary: } 48.6 \%\end{array}$ & $\begin{array}{l}0.63 \\
(0.22- \\
1.78)\end{array}$ & $p=0.439$ & $\begin{array}{l}\text { Primary: } 43.5 \% \\
\text { Secondary: } 62.1 \%\end{array}$ & $\begin{array}{l}0.47 \\
(0.17- \\
1.42)\end{array}$ & $p=0.264$ \\
\hline \multirow{2}{*}{$\begin{array}{l}\text { Intraoperative Use of } \\
\text { Autograft }\end{array}$} & \multirow{2}{*}{$\begin{array}{l}\text { Use of autograft: } 50.0 \% \text {, } \\
\text { No autograft: } 39.3 \%\end{array}$} & 1.55 & \multirow[t]{2}{*}{$p=0.591$} & \multirow{2}{*}{$\begin{array}{l}\text { Use of autograft: } \\
66.7 \% \text {, No autograft: } \\
37.5 \%\end{array}$} & \multirow{2}{*}{$\begin{array}{l}3.33 \\
(1.01- \\
10.95)\end{array}$} & \multirow[t]{2}{*}{$p=0.043$} \\
\hline & & $\begin{array}{l}(0.56- \\
4.47)\end{array}$ & & & & \\
\hline
\end{tabular}

Table 3 Clinical Pseudoarthrosis in patients with Spinal Tumor Resection and Instrumentation with Radiotherapy

\begin{tabular}{|lllll|}
\hline Patient & Age/Sex & Radiation Modality & Presentation & Outcome \\
\hline Patient 1 & $54 / \mathrm{M}$ & Conventional radiotherapy & Worsening pain with screw fracture & Conservative management \\
\hline Patient 2 & $79 / \mathrm{M}$ & Conventional radiotherapy & Worsening pain with radiographic non-union & Conservative management \\
\hline Patient 3 & $43 / \mathrm{M}$ & Conventional radiotherapy & Worsening pain with radiographic non-union & Conservative management \\
\hline Patient 4 & $73 / \mathrm{M}$ & Conventional radiotherapy & Worsening pain with broken rod & Revision surgery \\
\hline Patient 5 & $78 / \mathrm{M}$ & Proton radiotherapy & Worsening pain with screw fracture & Conservative management \\
\hline
\end{tabular}

\section{Effect of Radiotherapy Timing, Dose, and Photons versus Protons}

There was no significant difference in fusion outcomes for patients who received pre-operative radiotherapy ( $23 \%$ of patients, $n=14)$, compared to those who received post-operative radiotherapy at 6-months ( $42.9 \%$ versus $45.7 \%$, OR: $0.89, p=>0.999)$ and 12 -months ( $50.0 \%$ versus $57.1 \%$, OR: $0.65, p=0.734$ ). There was no significant difference in fusion rates between those patients treated with radiotherapy within 1 -month of surgery $(40 \%, n=24)$ and those treated more than 1 -month from their surgery at 6 -months $(42.9 \%$ versus $48.4 \%, 0 R: 0.80$, $\mathrm{p}=0.781)$ and 12 -months $(63.2 \%$ versus $48.3 \%$, OR: $1.84, p=0.382)$. There was no significant difference in 6 -month $(52.6 \%$ versus $31.8 \%, O R$ : $2.38, p=0.178)$ and 12 -month ( $64.5 \%$ versus $42.9 \%, O R: 2.42, p=0.160)$ fusion rates for patients who received $40 G y$ or less $(63 \%$ of patients, $\mathrm{n}=38$ ) of total radiation as compared to those who received a higher dose. Whether photons or protons were used did not significantly impact fusion outcomes at 6 -months ( $33.3 \%$ versus $56.1 \%$, OR: $0.39, \mathrm{p}=0.227$ ), and 12 -months ( $35.7 \%$ versus $64.1 \%, 0 R: 0.31, p=0.115$ ).

\section{Effect of Bone Graft and Tumor Type/Location}


There were 28 (46.7\%) patients who had use of intraoperative autograft during their surgery $(45.8 \%$ of focused cohort, $41.2 \%$ of conventional cohort, $\mathrm{p}=0.59$ ). All patients in the non-autograft group had intraoperative use of some form of allograft. Autograft modalities included iliac crest, femoral bone graft, and local bone not involved with tumor. At 6-months, there was no significant difference in the groups, with a $50.0 \%$ fusion rate for those with use of autograft, and $39.3 \%$ fusion rate for those without autograft $(\mathrm{OR}: 1.55, p=0.420)$. At 12-months, there was a significantly higher rate of fusion for those patients who had use of autograft at the time of surgery $(66.7 \%$ versus $37.5 \%$, OR: $3.33, \mathbf{p}=\mathbf{0 . 0 4 3 )}$. There were $25(41.7 \%)$ patients with primary tumors of the spinal cord or column and $35(58.3 \%)$ patients with secondary tumors of the spinal column. There was no significant difference between the groups for fusion rate at 6 -months $(40.0 \%$ versus $48.6 \%$, OR: $0.63, p=0.439)$ and 12 -months ( $43.5 \%$ versus $62.1 \%, O R: 0.47, p=0.264)$. There were 22 patients with cervical tumors, 23 patients with thoracic tumors, and 15 patients. There was no significant difference between the groups for 6-month $(p=0.529)$ and 12 -month fusion $(p=0.423)$, but the rate of fusion at 12 -months was $66.7 \%$ for patients with lumbar spine tumors, and $50 \%$ for those with cervical tumors and $50 \%$ for those with thoracic tumors.

\section{Discussion}

Our study shows that focused radiotherapy may be associated with improved fusion rates following resection and instrumentation in patients with spinal tumors when compared to conventional radiotherapy delivery modalities. Two prior studies attempted to answer this question, however they were both inadequately powered, highlighting the difficulty of answering this question for patients with spinal tumors such as metastasis, as these patients historically do not survive long enough to collect meaningful fusion data. [23][24] Improved survival outcomes due to recent advances in targeted therapies have allowed assessment of fusion status to be a feasible outcome. Our study also reveals that intraoperative use of autograft is associated with higher 12-month fusion rates for spinal tumor patients who receive peri-operative radiotherapy in conjunction with resection and instrumentation.

The theoretical benefit of focused radiotherapy lies in the delivering a higher treatment dose to a more precise location to maximize treatment effect at the surgical bed while limiting toxicity to the spinal cord, abdominal viscera, surrounding bone, and instrumentation hardware. [25][26] Our study found a significantly higher rate of fusion for patients with focused radiotherapy at 6-months (64.0\% versus $30.0 \%$, OR: $4.15, p=0.036$ ) and 12 -months ( $80.0 \%$ versus $42.1 \%, \mathrm{OR}: 5.50, \mathrm{p}=0.022$ ) compared to those who received radiation via a conventional delivery modality, indicating that the decreased radiation spillover into the surrounding bone is beneficial for fusion. A potential confounder was local spread of tumor into the fusion bed, as there was a near significant difference in the incidence of local recurrence at the time of fusion assessment ( 8.3 versus $35 \%, p=0.057$ ). While local recurrence was not an endpoint of this study, this appears to be an additional benefit of focused radiotherapy over conventional. While this may possibly play a small role in fusion, review of the imaging showed most cases of tumor progression to be ventral to the posterior elements, where fusion was assessed. Other factors such as the number of levels fused and chest wall resection have been found to play a role in hardware failure, but our study was well match with groups having similar numbers of levels fused. [27] A higher dose of radiation should theoretically have a more pronounced deleterious effect on bone growth and therefore a higher risk of non-union. A previous study indicated that more than 40Gy delivered to the surgical bed of an anterior reconstruction appeared to increase the risk of pseudoarthrosis. [28] We compared patients with a higher radiobiological dose of radiotherapy to those with a lower radiobiological dose, but there was no significant difference in fusion among the groups $(p=0.160)$. We found a higher incidence of clinically significant pseudoarthrosis in patients who received conventional radiotherapy when compared to those with conventional radiotherapy $(19.1 \%$ versus $0 \%, p=0.037)$. Although only one patient required re-operation, there is significant pain, disability, and loss of work associated with post-operative pseudoarthrosis. $[29,30]$

Expert opinion recommends at least one week between surgery and radiation to minimize the risk of wound healing complications, but there was insufficient literature to make recommendations for the timing of surgery as it relates to fusion. [12] Our study revealed no significant difference in the rate of fusion for those treated with radiotherapy within 1-month of surgery and those treated more than 1-month from their surgery at 6-months ( $\leq 1$ month: $42.9 \%,>1$ month: $48.4 \%, \mathrm{OR}: 0.80, \mathrm{p}=0.781$ ) and 12-months ( $\leq 1$ month: $64.5 \%,>1$ month: $42.9 \%$, OR: $2.42, p=0.160$ ). Interestingly, the fusion rate at 6 -months was nearly identical for the group treated within 1 -month, but the fusion rate at 12 months was slightly higher for the patients treated within 1-month of surgery. This indicates that receiving radiotherapy within 1-month of surgery does not appear to have a deleterious effect on fusion rates. Some studies have found no significant benefit of protons over photons for tumor control when the treatment dose is identical. [31] However, protons allow for delivery of a higher dose of radiation with a more rapid drop-off at the treatment field margins, causing less damage to unintended surrounding structures and therefore improved outcomes. [32][33] Our study did not note any difference in fusion outcomes for patients treated with photons compared to those treated with protons.

There is a wide array of bone graft products, with varying osteo-inductive, osteo-conductive, and osteo-genic properties which may help increase the likelihood for achieving a solid fusion. However, there is a contraindication for use of products like rhBMP in cancer patients 
because of a possible association between rhBMP and cancer, effectively eliminating its use in spine tumor patients. [34][35][36] Inability to use these types of products compounded with the use of peri-operative radiation explains the difficulty with obtaining a bony fusion in this patient population. Our study found a higher 12-month fusion rate when autografts such as iliac crest and femoral bone grafts were used compared to patients who received allograft and synthetic bone products $(66.7 \%$ versus $37.5 \%, 0 R$ : 3.33 , $p=0.043)$. This finding appears to be consistent with the available evidence for non-neoplastic cases, as some studies found a better fusion rate when using autograft compared to synthetic allograft bone. [37-39][40][41]

\section{Limitations}

The question of fusion outcomes after spinal tumor resection and radiotherapy has historically been challenging to answer due to many inherent limitations of this patient population. Secondary tumors of the spinal column are the most common, and these patients often succumb to their systemic disease burden within a year of surgery. This limited the available data, as most of the patients who received radiation after resection of their spinal tumors died prior to the typical time frame one would expect to see fusion. This limited the ability to assess long term fusion, which would be most ideal. Our study started with over 1,200 potential patients, but after exclusion, there were 60 patients remaining. Another limitation of this study was our inability to factor in how much of the area of intended arthrodesis was included in the radiation treatment field. For multi-level posterior constructs, most of the instrumentation field will likely be out of the treatment field, but we were unable to account for this. We would ideally use CT imaging to assess fusion in all patients, but only x-ray imaging was available for $12 \%(n=7)$ of patients. There was also a fair amount of heterogeneity for the patients included. Patients with resection of a primary bone tumor such as chordoma may have a large bony gap making fusion much more challenging. Many of the chordoma patients received proton radiotherapy, and therefore were not included in the primary analysis. Also, there was no difference between the groups for the incidence of primary tumors ( $p=>0.999$ ). Despite these limitations, this appears to be the best available data to support one method of peri-operative radiotherapy over another. A strength of this study is the external validity, being comprised of patients from tertiary care institutions in three different geographical regions of the United States.

\section{Conclusions}

Based on our comparison of peri-operative focused radiotherapy and conventional radiotherapy for treatment of spinal tumor patients with surgical resection and instrumentation, focused radiotherapy appears to have a better fusion rate at 12-months as well as lower incidence of clinical pseudoarthrosis. Although no definitive recommendations can be made for the ideal timing of peri-operative radiotherapy, the use of radiotherapy within a month of surgery does not appear to have a significant deleterious effect on fusion. Surgeons should consider use of autograft when instrumenting spinal tumor patients who will receive peri-operative radiotherapy, as this may increase the likelihood for a solid fusion.

\section{Declarations}

Funding: 0.O.A. is supported by Neurosurgery Research and Education Foundation Funding, but this funding is not directly related to this project.

Conflict of Interest: All authors report they have no conflicts of interest.

Ethical approval: All procedures performed in studies involving human participants were in accordance with the ethical standards of the institutional and/or national research committee and with the 1964 Helsinki declaration and its later amendments or comparable ethical standards. IRB approval was obtained for this study.

Statements and Declarations: Authors report no financial competing interests. O.O.A. is supported by Neurosurgery Research and Education Foundation Funding.

Author contributions: OOA: writing manuscript, data collection, statistical analysis, reviewed final, GD: writing manuscript, data collection, statistical analysis AG: data collection, JM: data collection, SS: data collection, critically revised manuscript, RK: figure preparation, critically revised manuscript, DT: critically revised manuscript,JS: critically revised manuscript, KM: critically revised manuscript, SV: critically revised manuscript, DB: data collection, MC: critically revised manuscript, MB: critically revised manuscript, JM: critically revised manuscript, MK: critically revised manuscript, $A Q$ : critically revised manuscript, KA: critically revised manuscript, study supervision

Data availability statement: Not applicable, electronic medical record data is protected by institution

\section{References}


1. Miften M, Olch A, Mihailidis D, Moran J, Pawlicki T, Molineu A, Li H, Wijesooriya K, Shi J, Xia P, Papanikolaou N, Low DA (2018) Tolerance limits and methodologies for IMRT measurement-based verification QA: Recommendations of AAPM Task Group No. 218. Med Phys 45: e53-e83 doi:10.1002/mp.12810

2. Ma L, Wang L, Tseng CL, Sahgal A (2017) Emerging technologies in stereotactic body radiotherapy. Chin Clin Oncol 6: S12 doi:10.21037/cco.2017.06.19

3. Martin AG, Thomas SJ, Harden SV, Burnet NG (2015) Evaluating competing and emerging technologies for stereotactic body radiotherapy and other advanced radiotherapy techniques. Clin Oncol (R Coll Radiol) 27: 251-259 doi:10.1016/j.clon.2015.01.034

4. Zeng KL, Tseng CL, Soliman H, Weiss Y, Sahgal A, Myrehaug S (2019) Stereotactic Body Radiotherapy (SBRT) for Oligometastatic Spine Metastases: An Overview. Front Oncol 9: 337 doi:10.3389/fonc.2019.00337

5. Redmond KJ, Robertson S, Lo SS, Soltys SG, Ryu S, McNutt T, Chao ST, Yamada Y, Ghia A, Chang EL, Sheehan J, Sahgal A (2017) Consensus Contouring Guidelines for Postoperative Stereotactic Body Radiation Therapy for Metastatic Solid Tumor Malignancies to the Spine. Int J Radiat Oncol Biol Phys 97: 64-74 doi:10.1016/j.ijrobp.2016.09.014

6. Redmond KJ, Sciubba D, Khan M, Gui C, Lo SL, Gokaslan ZL, Leaf B, Kleinberg L, Grimm J, Ye X, Lim M (2020) A Phase 2 Study of PostOperative Stereotactic Body Radiation Therapy (SBRT) for Solid Tumor Spine Metastases. Int J Radiat Oncol Biol Phys 106: 261-268 doi:10.1016/j.ijrobp.2019.10.011

7. Longo M, De la Garza Ramos R, Gelfand Y, Echt M, Kinon MD, Yassari R (2019) Incidence and Predictors of Hardware Failure After Instrumentation for Spine Metastasis: A Single-Institutional Series. World Neurosurg 125: e1170-e1175 doi:10.1016/j.wneu.2019.01.272

8. Gouk SS, Lim TM, Teoh SH, Sun WQ (2008) Alterations of human acellular tissue matrix by gamma irradiation: histology, biomechanical property, stability, in vitro cell repopulation, and remodeling. J Biomed Mater Res B Appl Biomater 84: 205-217 doi:10.1002/jbm.b.30862

9. She C, Shi GL, Xu W, Zhou XZ, Li J, Tian Y, Li J, Li WH, Dong QR, Ren PG (2016) Effect of low-dose X-ray irradiation and Ti particles on the osseointegration of prosthetic. J Orthop Res 34: 1688-1696 doi:10.1002/jor.23179

10. Chen M, Huang Q, Xu W, She C, Xie ZG, Mao YT, Dong QR, Ling M (2014) Low-dose X-ray irradiation promotes osteoblast proliferation, differentiation and fracture healing. PLoS One 9: e104016 doi:10.1371/journal.pone.0104016

11. Song XS, Zhou XZ, Zhang G, Dong QR, Qin L (2010) Low-dose X-ray irradiation promotes fracture healing through up-regulation of vascular endothelial growth factor. Med Hypotheses 75: 522-524 doi:10.1016/j.mehy.2010.07.012

12. Itshayek E, Cohen JE, Yamada Y, Gokaslan Z, Polly DW, Rhines LD, Schmidt MH, Varga PP, Mahgarefteh S, Fraifeld S, Gerszten PC, Fisher CG (2014) Timing of stereotactic radiosurgery and surgery and wound healing in patients with spinal tumors: a systematic review and expert opinions. Neurol Res 36: 510-523 doi:10.1179/1743132814Y.0000000380

13. Akinduro OO, Garcia DP, Domingo RA, Vivas-Buitrago T, Sousa-Pinto B, Bydon M, Clarke MJ, Gokaslan ZL, Kalani MA, Abode-lyamah K, Quinones-Hinojosa A (2021) Cervical chordomas: multicenter case series and meta-analysis. J Neurooncol 153: 65-77 doi:10.1007/s11060-021-03742-6

14. Akinduro OO, Suarez-Meade P, Garcia D, Brown DA, Sarabia-Estrada R, Attia S, Gokaslan ZL, Quinones-Hinojosa A (2021) Targeted Therapy for Chordoma: Key Molecular Signaling Pathways and the Role of Multimodal Therapy. Target Oncol 16: 325-337 doi:10.1007/s11523-021-00814-5

15. Bydon M, De la Garza-Ramos R, Abt NB, Gokaslan ZL, Wolinsky JP, Sciubba DM, Bydon A, Witham TF (2014) Impact of smoking on complication and pseudarthrosis rates after single- and 2-level posterolateral fusion of the lumbar spine. Spine (Phila Pa 1976) 39: 1765-1770 doi:10.1097/BRS.0000000000000527

16. Watkins MB (1964) Posterolateral fusion in pseudarthrosis and posterior element defects of the lumbosacral spine. Clin Orthop Relat Res 35: 80-85

17. Zhang M, Appelboom G, Ratliff JK, Soltys SG, Adler JR, Jr., Park J, Chang SD (2018) Radiographic Rate and Clinical Impact of Pseudarthrosis in Spine Radiosurgery for Metastatic Spinal Disease. Cureus 10: e3631 doi:10.7759/cureus.3631

18. Sahgal A, Roberge D, Schellenberg D, Purdie TG, Swaminath A, Pantarotto J, Filion E, Gabos Z, Butler J, Letourneau D, Masucci GL, Mulroy L, Bezjak A, Dawson LA, Parliament M, The Canadian Association of Radiation Oncology-Stereotactic Body Radiotherapy Task F (2012) The Canadian Association of Radiation Oncology scope of practice guidelines for lung, liver and spine stereotactic body radiotherapy. Clin Oncol (R Coll Radiol) 24: 629-639 doi:10.1016/j.clon.2012.04.006

19. Chang JH, Shin JH, Yamada YJ, Mesfin A, Fehlings MG, Rhines LD, Sahgal A (2016) Stereotactic Body Radiotherapy for Spinal Metastases: What are the Risks and How Do We Minimize Them? Spine (Phila Pa 1976) 41 Suppl 20: S238-S245 doi:10.1097/BRS.0000000000001823

Page $9 / 13$ 
20. Hartsell WF, Scott CB, Bruner DW, Scarantino CW, Ivker RA, Roach M, 3rd, Suh JH, Demas WF, Movsas B, Petersen IA, Konski AA, Cleeland CS, Janjan NA, DeSilvio M (2005) Randomized trial of short- versus long-course radiotherapy for palliation of painful bone metastases. J Natl Cancer Inst 97: 798-804 doi:10.1093/jnci/dji139

21. Indelicato DJ, Rotondo RL, Begosh-Mayne D, Scarborough MT, Gibbs CP, Morris CG, Mendenhall WM (2016) A Prospective Outcomes Study of Proton Therapy for Chordomas and Chondrosarcomas of the Spine. Int J Radiat Oncol Biol Phys 95: $297-303$ doi:10.1016/j.ijrobp.2016.01.057

22. Lenke LG, Bridwell KH, Bullis D, Betz RR, Baldus C, Schoenecker PL (1992) Results of in situ fusion for isthmic spondylolisthesis. J Spinal Disord 5: 433-442 doi:10.1097/00002517-199212000-00008

23. Harel R, Chao S, Krishnaney A, Emch T, Benzel EC, Angelov L (2010) Spine instrumentation failure after spine tumor resection and radiation: comparing conventional radiotherapy with stereotactic radiosurgery outcomes. World Neurosurg 74: 517-522 doi:10.1016/j.wneu.2010.06.037

24. Kim TK, Cho W, Youn SM, Chang UK (2016) The Effect of Perioperative Radiation Therapy on Spinal Bone Fusion Following Spine Tumor Surgery. J Korean Neurosurg Soc 59: 597-603 doi:10.3340/jkns.2016.59.6.597

25. Cox BW, Spratt DE, Lovelock M, Bilsky MH, Lis E, Ryu S, Sheehan J, Gerszten PC, Chang E, Gibbs I, Soltys S, Sahgal A, Deasy J, Flickinger J, Quader M, Mindea S, Yamada Y (2012) International Spine Radiosurgery Consortium consensus guidelines for target volume definition in spinal stereotactic radiosurgery. Int J Radiat Oncol Biol Phys 83: e597-605 doi:10.1016/j.ijrobp.2012.03.009

26. Redmond KJ, Lo SS, Soltys SG, Yamada Y, Barani IJ, Brown PD, Chang EL, Gerszten PC, Chao ST, Amdur RJ, De Salles AA, Guckenberger M, Teh BS, Sheehan J, Kersh CR, Fehlings MG, Sohn MJ, Chang UK, Ryu S, Gibbs IC, Sahgal A (2017) Consensus guidelines for postoperative stereotactic body radiation therapy for spinal metastases: results of an international survey. J Neurosurg Spine 26: 299306 doi:10.3171/2016.8.SPINE16121

27. Amankulor NM, Xu R, lorgulescu JB, Chapman T, Reiner AS, Riedel E, Lis E, Yamada Y, Bilsky M, Laufer I (2014) The incidence and patterns of hardware failure after separation surgery in patients with spinal metastatic tumors. Spine J 14: 1850-1859 doi:10.1016/j.spinee.2013.10.028

28. Emery SE, Hughes SS, Junglas WA, Herrington SJ, Pathria MN (1994) The fate of anterior vertebral bone grafts in patients irradiated for neoplasm. Clin Orthop Relat Res: 207-212

29. Dede O, Thuillier D, Pekmezci M, Ames CP, Hu SS, Berven SH, Deviren V (2015) Revision surgery for lumbar pseudarthrosis. Spine J 15: 977-982 doi:10.1016/j.spinee.2013.05.039

30. Kim YJ, Bridwell KH, Lenke LG, Rinella AS, Edwards C, 2nd (2005) Pseudarthrosis in primary fusions for adult idiopathic scoliosis: incidence, risk factors, and outcome analysis. Spine (Phila Pa 1976) 30: 468-474 doi:10.1097/01.brs.0000153392.74639.ea

31. Cheng JY, Liu CM, Wang YM, Hsu HC, Huang EY, Huang TT, Lee CH, Hung SP, Huang BS (2020) Proton versus photon radiotherapy for primary hepatocellular carcinoma: a propensity-matched analysis. Radiat Oncol 15: 159 doi:10.1186/s13014-020-01605-4

32. Carbonara R, Di Rito A, Monti A, Rubini G, Sardaro A (2019) Proton versus Photon Radiotherapy for Pediatric Central Nervous System Malignancies: A Systematic Review and Meta-Analysis of Dosimetric Comparison Studies. J Oncol 2019: 5879723 doi:10.1155/2019/5879723

33. Zietman AL, Bae K, Slater JD, Shipley WU, Efstathiou JA, Coen JJ, Bush DA, Lunt M, Spiegel DY, Skowronski R, Jabola BR, Rossi CJ (2010) Randomized trial comparing conventional-dose with high-dose conformal radiation therapy in early-stage adenocarcinoma of the prostate: long-term results from proton radiation oncology group/american college of radiology 95-09. J Clin Oncol 28: 1106-1111 doi:10.1200/JC0.2009.25.8475

34. Delawi D, Dhert WJ, Rillardon L, Gay E, Prestamburgo D, Garcia-Fernandez C, Guerado E, Specchia N, Van Susante JL, Verschoor N, van Ufford HM, Oner FC (2010) A prospective, randomized, controlled, multicenter study of osteogenic protein-1 in instrumented posterolateral fusions: report on safety and feasibility. Spine (Phila Pa 1976) 35: 1185-1191 doi:10.1097/BRS.0b013e3181d3cf28

35. Devine JG, Dettori JR, France JC, Brodt E, McGuire RA (2012) The use of rhBMP in spine surgery: is there a cancer risk? Evid Based Spine Care J 3: 35-41 doi:10.1055/s-0031-1298616

36. Vaccaro AR, Whang PG, Patel T, Phillips FM, Anderson DG, Albert TJ, Hilibrand AS, Brower RS, Kurd MF, Appannagari A, Patel M, Fischgrund JS (2008) The safety and efficacy of OP-1 (rhBMP-7) as a replacement for iliac crest autograft for posterolateral lumbar arthrodesis: minimum 4-year follow-up of a pilot study. Spine J 8: 457-465 doi:10.1016/j.spinee.2007.03.012

37. Orief T, Ramadan I, Seddik Z, Kamal M, Rahmany M, Takayasu M (2010) Comparative evaluation of bone-filled Polymethylmethacrylate implant, autograft fusion, and Polyetheretherketone cervical cage fusion for the treatment of single -level cervical disc disease. Asian $\mathrm{J}$ Neurosurg 5: 46-56 
38. Barlocher CB, Barth A, Krauss JK, Binggeli R, Seiler RW (2002) Comparative evaluation of microdiscectomy only, autograft fusion, polymethylmethacrylate interposition, and threaded titanium cage fusion for treatment of single-level cervical disc disease: a prospective randomized study in 125 patients. Neurosurg Focus 12: E4 doi:10.3171/foc.2002.12.1.5

39. Buser Z, Brodke DS, Youssef JA, Meisel HJ, Myhre SL, Hashimoto R, Park JB, Tim Yoon S, Wang JC (2016) Synthetic bone graft versus autograft or allograft for spinal fusion: a systematic review. J Neurosurg Spine 25: 509-516 doi:10.3171/2016.1.SPINE151005

40. Hsu CJ, Chou WY, Teng HP, Chang WN, Chou YJ (2005) Coralline hydroxyapatite and laminectomy-derived bone as adjuvant graft material for lumbar posterolateral fusion. J Neurosurg Spine 3: 271-275 doi:10.3171/spi.2005.3.4.0271

41. Kunakornsawat S, Kirinpanu A, Piyaskulkaew C, Sathira-Angkura V (2013) A comparative study of radiographic results using HEALOS collagen-hydroxyapatite sponge with bone marrow aspiration versus local bone graft in the same patients undergoing posterolateral lumbar fusion. J Med Assoc Thai 96: 929-935

\section{Figures}
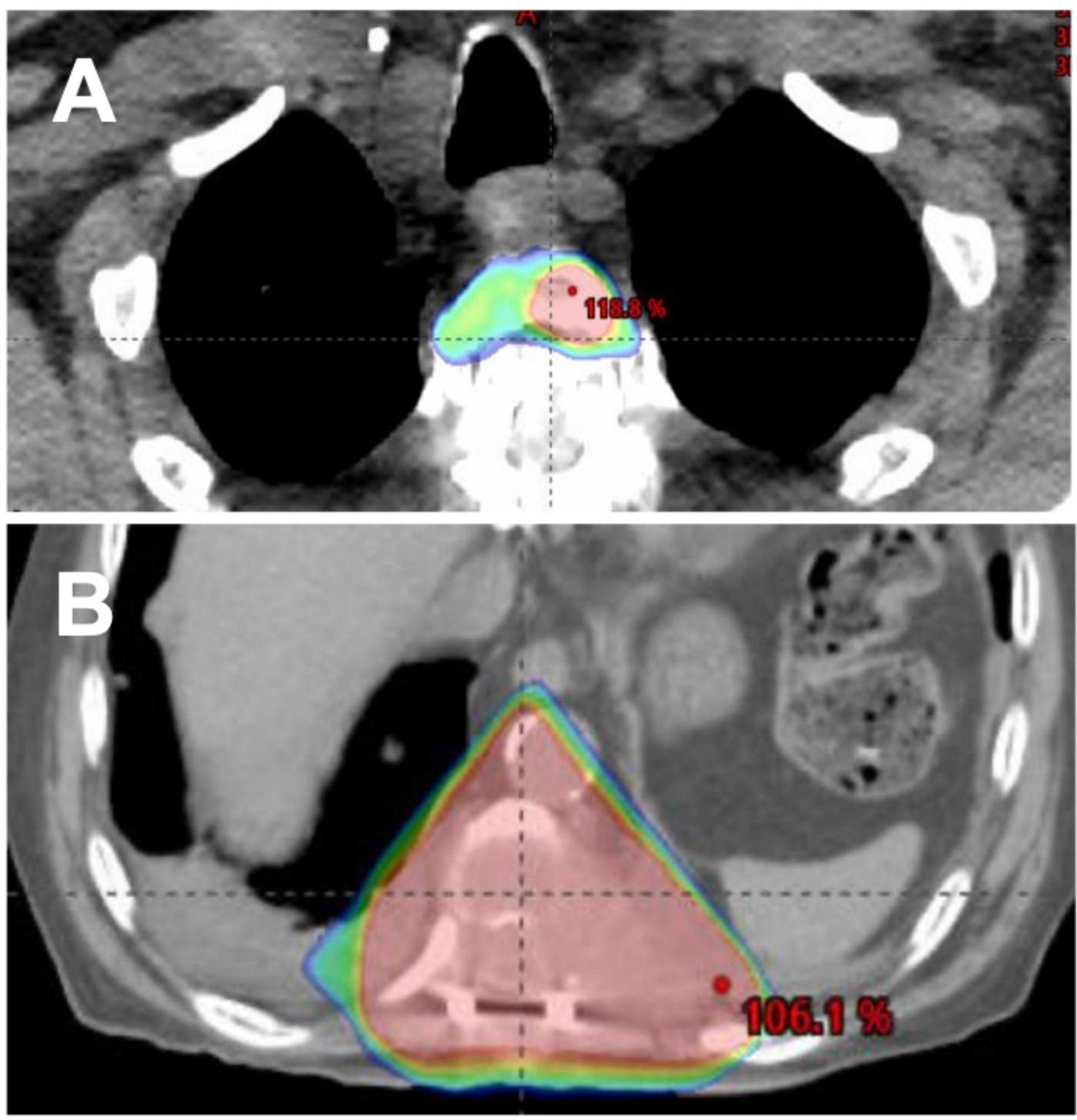

\section{Figure 1}

Planning computed tomography (CT) demonstrating treatment fields for patients with spinal tumors and instrumentation. A) Treatment fields for a 76-year-old man with metastatic renal cell carcinoma who underwent a C6-T4 instrumented fusion and resection of his tumor followed by 30 Gray of stereotactic body radiotherapy (SBRT) in 3 fractions. Treatment demonstrated ranging from at least 100\% of the prescription dose in red to $80 \%$ of the prescription dose in blue. At 12-months the patient had evidence of Lenke grade B fusion. B) Treatment fields for a 79-year-old man with metastatic hepatocellular carcinoma who underwent a T11-L2 instrumented fusion and resection of his tumor followed by 8 Gy of conventional external beam radiotherapy in 1 fraction. Treatment demonstrated ranging from at 
least $100 \%$ of the prescription dose in red to $80 \%$ of the prescription dose in blue. The patient had a wound dehiscence requiring return to the operating room and a Lenke grade $\mathrm{C}$ fusion at 12-months.

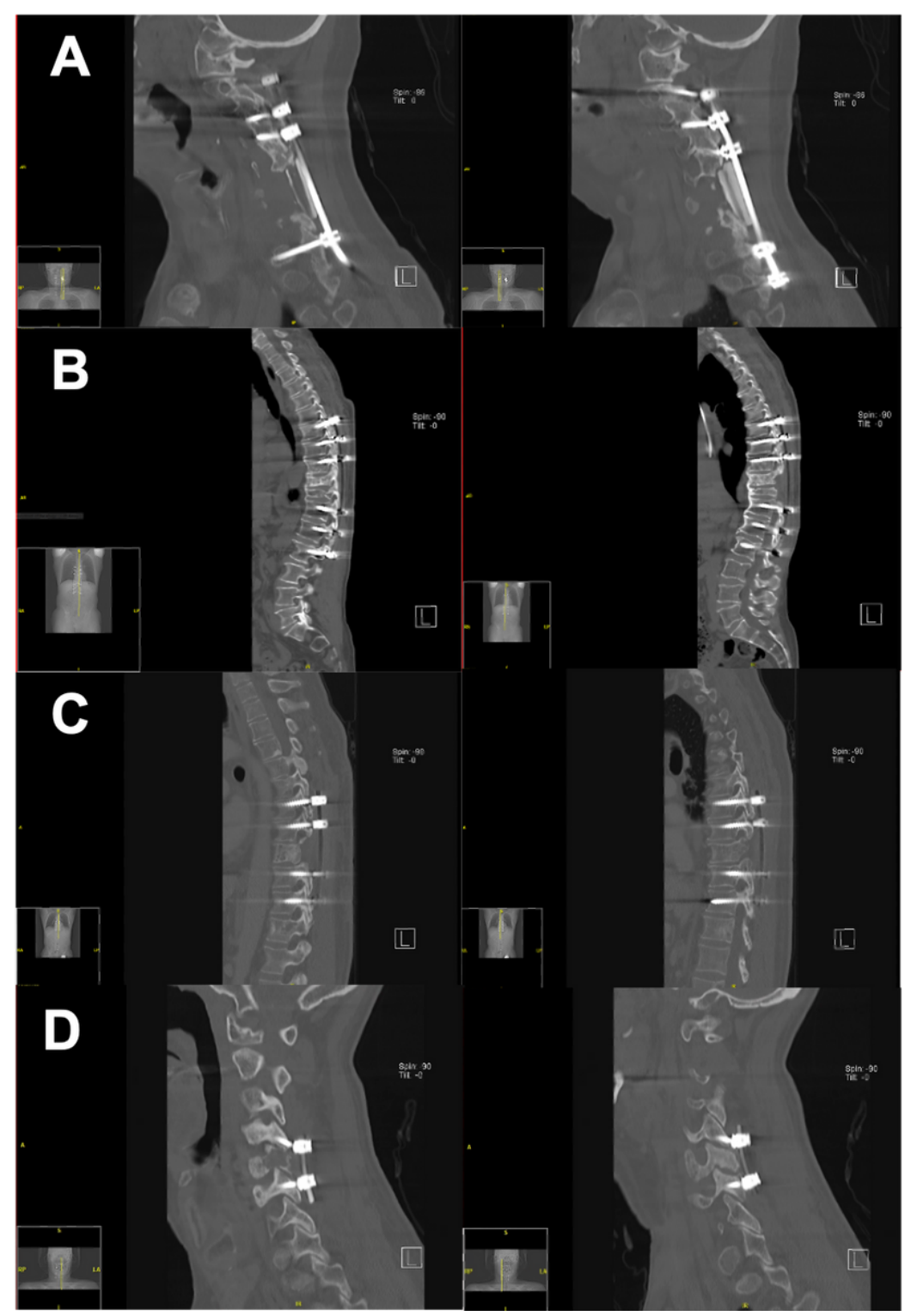

\section{Figure 2}

Sagittal CT scans showing fusion Grades according to the Lenke Classification. A) Grade A: solid fusion with bilateral solid stout fusion present; B) Grade B: probably solid fusion with unilateral stout fusion mass and contralateral thin fusion mass; C) Grade C: probably not solidly fused with a thin unilateral fusion mass and probable pseudarthrosis on the contralateral side; D) Grade D: definitely not solidly fused with thin fusion masses bilaterally with obvious pseudarthrosis or bone graft dissolution bilaterally. 


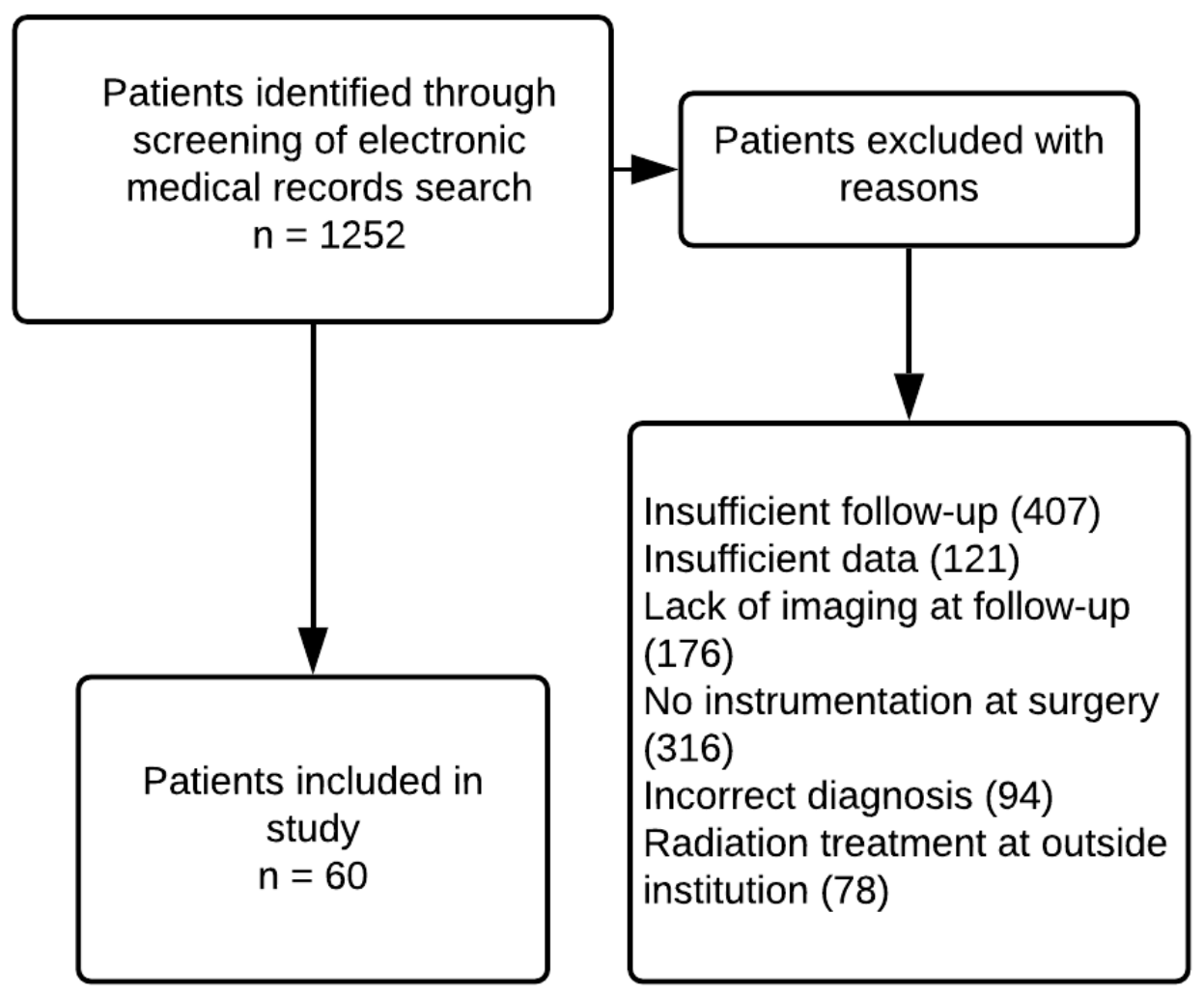

Figure 3

Flow diagram of included patients with spinal tumor resection included in our analysis. 